\title{
Usefulness of the neutrophil-to-lymphocyte, monocyte-to-lymphocyte and lymphocyte-to-platelet ratios for the prognosis of COVID-19-associated complications
}

\author{
Christian O. Ramos-Peñafiel, ${ }^{*}{ }^{*}$ Brenda Santos-González, ${ }^{1}$ Eder N. Flores-López, ${ }^{1}$ \\ Francisco Galván-Flores, ${ }^{1}$ Lucía Hernández-Vázquez, ${ }^{1}$ Adrián Santoyo-Sánchez, ${ }^{2}$ \\ Rosaura Montes de Oca-Yemha, ${ }^{1}$ Mónica Bejarano-Rosales, ${ }^{3}$ Érika Rosas-González, ${ }^{3}$ \\ Irma Olarte-Carrillo, ${ }^{2}$ Carlos Martínez-Murillo ${ }^{2}$ and Adolfo Martínez-Tovar ${ }^{2}$ \\ ${ }^{1}$ Department of Internal Medicine, Cuautitlán General Hospital, Instituto de Salud del Estado de México, State of Mexico; ${ }^{2}$ Hematology Department,

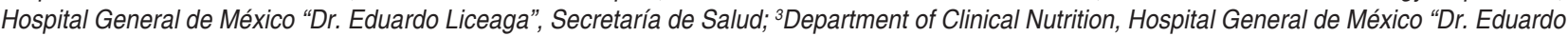 \\ Liceaga", Secretaría de Salud. Mexico City. Mexico
}

\begin{abstract}
Introduction: Various biomarkers based on blood counts have been useful for the prognosis of patients critically ill with COVID-19. Objective: To describe the usefulness of the neutrophil-to-lymphocyte (NLR), monocyte-to-lymphocyte (MLR) and lymphocyte-to-platelet (LPR) ratios for the prognosis of mortality and ventilatory support requirement for COVID-19. Method: Retrospective cohort of clinical records of patients with COVID-19 who required hospital care. Results: One-hundred and twenty-five cases were analyzed; mean age was 51 years, and $60 \%$ were of the male gender; $21.6 \%$ had type 2 diabetes mellitus, and $18.4 \%$ had hypertension. Mean leukocyte count was $9.5 \times 10^{3} / \mu \mathrm{L}$, with a neutrophil mean of $8.0 \times 10^{3} / \mu \mathrm{L}$. Mean NLR was 12.01, while for MLR it was 0.442, and for LPR, 373.07. Regarding the area under the curve, the following values were recorded for mortality: 0.594 for NLR, 0.628 for MLR and 0.505 for LPR; as for mechanical ventilation, the values were 0.581 for NLR, 0.619 for MLR and 0.547 for LPR. In the univariate analysis, an NLR value > 13 (OR: 2.750, $p=0.001$ ) and an MLR of $>0.5$ (OR: 2.069, $p=0.047$ ) were associated with mortality; LPR showed no impact on mortality or respiratory support. Conclusion: NLR and MLR are useful for predicting mortality in patients with COVID-19.
\end{abstract}

KEY WORDS: Neutrophils. Lymphocytes. Platelets. COVID-19. Prognostic index.

\section{Utilidad de los índices neutrófilo/linfocito, monocito/linfocito y linfocito/plaqueta para el pronóstico de complicaciones asociadas a COVID-19}

\section{Resumen}

Introducción: Diversos biomarcadores basados en conteos sanguíneos han sido de utilidad para el pronóstico de los pacientes en estado crítico por COVID-19. Objetivo: Describir la utilidad de los índices neutrófilo/linfocito (INL), monocito/linfocito (IML) y linfocito/plaqueta (IPL) para el pronóstico de la mortalidad y necesidad de soporte ventilatorio por COVID-19. Método: Cohorte retrospectiva de registros clínicos de pacientes con COVID-19 que requirieron atención hospitalaria. Resultados: Se analizaron 125 casos, la edad media fue de 51 años y $60 \%$, del sexo masculino; $21.6 \%$ padecía diabetes mellitus tipo 2 y $18.4 \%$, hipertensión. La media de leucocitos fue $9.5 \times 10^{3} / \mu \mathrm{L}$ y la de neutrófilos, de $8.0 \times 10^{3} / \mu \mathrm{L}$. La media

Correspondence:

${ }^{*}$ Christian O. Ramos-Peñafiel

E-mail: leukemiachop @ hotmail.com
Gac Med Mex. 2020;156:405-411

Contents available at PubMed

www.gacetamedicademexico.com

0016-3813/@ 2020 Academia Nacional de Medicina de México, A.C.. Published by Permanyer. This is an open access article under the CC BY-NC-ND license (http://creativecommons.org/licenses/by-nc-nd/4.0/). 
del INL fue de 12.01; del IML, de 0.442 y del IPL, de 373.07. Respecto al área bajo la curva se registraron los siguientes valores en cuanto a mortalidad: INL, 0.594; IML, 0.628 e ILP, 0.505; en cuanto a ventilación mecánica: INL, $0.581 ;$ IML, 0.619 e ILP, 0.547. En el análisis univariado, INL > $13(R M=2.750, p=0.001)$ e $I M L>0.5(R M=2.069, p=0.047)$ se asociaron a mortalidad; ILP no mostró impacto en la mortalidad ni en el soporte respiratorio. Conclusión: INL e IML son de utilidad para predecir la mortalidad en pacientes con COVID-19.

PALABRAS CLAVE: Neutrófilos. Linfocitos. Plaquetas. COVID-19. Índice pronóstico.

\section{Introduction}

At the moment of this report, the coronavirus (SARSCoV-2) pandemic is at its transmission peak $(9,937,618$ cases worldwide), with Latin America being the main affected region $(2,505,593$ cases in the United States, 1,313,667 in Brazil, 275,989 in Peru). ${ }^{1}$ In Mexico, most cases are concentrated in Mexico City and neighboring municipalities, with a mortality of 26,381 people. ${ }^{2}$ Regarding risk factors, most information has been obtained from different series in Wuhan, China. Both age and a history of hypertension or diabetes have been established as the main clinical risk factors; ${ }^{3}$ the male gender has been associated with a higher risk of complications and mortality (2.8\% and $1.7 \%) .{ }^{4}$ Guan et al. evaluated the impact of the combination of different comorbidities in 1,590 patients from 575 hospitals in China: chronic lung disease (relative risk $[R R]=2.681$ ), diabetes $(R R=1.59)$, hypertension $(R R=1.58)$ and cancer $(\mathrm{RR}=3.5)$ were the main risk factors for SARSCoV-2 infection. ${ }^{5}$ Together with clinical data, various laboratory parameters have been associated with disease severity, mainly blood counts alterations, elevated lactate dehydrogenase and D-dimer drastic elevation. ${ }^{6}$ Alterations such as lymphopenia have been associated with severe SARS-CoV-2 infection (odds ratio $[\mathrm{OR}]=2.99)^{7}$

There are various ratios based on different cell counts, with one of the most widely used being the neutrophil-to-lymphocyte ratio (NLR), the usefulness of which has been shown in conditions that range from infectious to inflammatory diseases or cancer. ${ }^{8}$ In patients with community-acquired pneumonia, NLR values higher than 7.2 have been associated with severe respiratory complications. ${ }^{9}$ In SARSCoV-2, NLR values $>4$ have been associated with hospital complications and intensive care unit admission. ${ }^{10}$ Another blood parameter is platelet-to-lymphocyte ratio (PLR), the usefulness of which has been evaluated in respiratory diseases, although a smaller area under the curve has been obtained in comparison with NLR $(0.74$ vs. 0.88$) .{ }^{11}$ The last ratio that is used is the monocyte-to-lymphocyte ratio $(M L R)$, with its greatest usefulness being in inflammatory diseases as a predictor of acute gout attacks or osteoarthritis, where its increase has been associated with joint exacerbations. ${ }^{12,13}$

SARS-CoV-2 infection is characterized by an unregulated systemic inflammation called "cytokine storm", the development of which is based on an uncontrolled activation of the innate immune response, which activates the endothelium, the complement and the hemostatic system. ${ }^{14,15}$ This activation modifies different cell counts, causing deep lymphopenia, leukocytosis and neutrophilia. The purpose of this study was to identify the usefulness of the NLR, MLR and LPR ratios in the prognosis of patients with SARS-CoV infection in a limited-resource hospital.

\section{Method}

The Cuautitlán General Hospital is a regional hospital that serves 15 municipalities in the State of Mexico. It has 120 beds, out of which 72 were converted for the care of COVID-19 patients, eight beds were added to the emergency area, and the Intensive Care Unit continued providing care to critically ill patients without SARS-CoV-2 infection.

Hospitalized patients with a confirmed diagnosis of SARS-CoV-2 infection treated from April 10 to May 15, 2020, were included in this study. Treatment of each case was according to treating physician indications, with the main combination used being azithromycin with hydroxychloroquine, or addition of oseltamivir or ritonavir-lopinavir. All patients received anticoagulant therapy with low molecular weight heparin. The decision and the time to start ventilatory support was in accordance with patient clinical conditions.

Blood count analysis was carried out in an automated way with a Beckman Coulter $\mathrm{LH} 750^{\circledR}$ cytometer (Brea, California, USA), and analysis of the different ratios was performed based on the blood counts at hospital admission. Calculation of the ratios (NLR, 
Table 1. Main characteristics of hospitalized patients with COVID-19

\begin{tabular}{|c|c|c|c|c|c|c|c|}
\hline Variable & \multicolumn{2}{|c|}{ Overall $(n=125)$} & \multicolumn{2}{|c|}{ Alive $(n=71)$} & \multicolumn{2}{|c|}{ Dead $(n=54)$} & $p$ \\
\hline \multirow[t]{2}{*}{ Age, years (range) } & \multicolumn{2}{|c|}{$51(24-85)$} & \multicolumn{2}{|c|}{$50(24-85)$} & \multicolumn{2}{|c|}{$52(25-78)$} & 0.485 \\
\hline & $\mathrm{n}$ & $\%$ & $\mathrm{n}$ & $\%$ & $\mathrm{n}$ & $\%$ & \\
\hline $\begin{array}{l}\text { Gender } \\
\text { Males } \\
\text { Females }\end{array}$ & $\begin{array}{l}80 \\
45\end{array}$ & $\begin{array}{l}64 \\
35\end{array}$ & $\begin{array}{l}48 \\
23\end{array}$ & $\begin{array}{l}67.6 \\
32.4\end{array}$ & $\begin{array}{l}32 \\
22\end{array}$ & $\begin{array}{l}59.3 \\
40.7\end{array}$ & 0.219 \\
\hline Diabetes & 27 & 21.6 & 20 & 28.2 & 07 & 13 & 0.032 \\
\hline \multirow[t]{2}{*}{ Hypertension } & 24 & 19.2 & 15 & 21.1 & 09 & 16.7 & 0.348 \\
\hline & Mean & Range & Mean & Range & Mean & Range & \\
\hline Leukocytes (x103/uL) & 9.5 & $3.4-22.7$ & 9.1 & $3.4-22.7$ & 10 & $5.2-22.7$ & 0.169 \\
\hline Neutrophils $\left(x 10^{3} / \mu \mathrm{L}\right)$ & 8.0 & 2.1-18.5 & 7.58 & $2.1-18.5$ & 8.5 & $3.6-18.1$ & 0.125 \\
\hline Lymphocytes (x103/hL) & 0.91 & $0-5.76$ & 0.92 & $0.1-3.7$ & 0.90 & $0.5-7.6$ & 0.899 \\
\hline 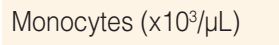 & 0.33 & $0-1.14$ & 0.30 & $0-1.14$ & 0.36 & $06-1.14$ & 0.116 \\
\hline 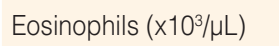 & 0.02 & $0-0.3$ & 0.02 & $0-0.2$ & 0.02 & $0-0.3$ & 0.801 \\
\hline Hemoglobin ( $\mathrm{g} / \mathrm{dL})$ & 14.9 & $7-20.8$ & 15.3 & 12.3-19.8 & 14.3 & $7-20.8$ & 0.011 \\
\hline Platelets $\left(\times 10^{3} / \mu \mathrm{L}\right)$ & 233 & $71-601$ & 240.2 & $108-562$ & 223 & $71-672$ & 0.405 \\
\hline NLR & 12.01 & $1.9-56$ & 10.56 & $2.0-46$ & 13.92 & $1.9-56$ & 0.052 \\
\hline MLR & 0.44 & $0-2$ & 0.37 & $0-1$ & 0.53 & $0-2$ & 0.004 \\
\hline PLR & 373 & $0-2136$ & 338 & $22.5-1694$ & 419 & $0-2136$ & 0.192 \\
\hline
\end{tabular}

$\mathrm{NLR}=$ neutrophil-to-lymphocyte ratio, MLR = monocyte-to-lymphocyte ratio, $\mathrm{PLR}=$ platelet-to-lymphocyte ratio.

MLR, PLR) was executed with the MDCalc program (https://www.mdcalc.com). ${ }^{16}$

For statistical analysis, the SPSS ${ }^{\circledR}$ program, version 25 for Windows (IBM, Armonk, New York, USA), was used to describe mean blood count values. The difference of values between the groups of patients with complications was carried out using Student's t-test ( $p \leq 0.05,95 \%$ confidence interval $[\mathrm{Cl}])$. Calculation of the area under the curve (AUC) of all three ratios with regard to complications (respiratory support and death) was carried out; by establishing the cutoff point of the ratios with regard to mortality, survival was analyzed using the Kaplan-Meier method. The difference between groups was established using the log-rank test.

\section{Results}

Out of 147 patients who were provided care to, 125 were included in the study; $64 \%(n=80)$ corresponded to the male gender, and mean age was 51.6 years, with females being slightly older in a non-significant way (53 vs. 50 years, $p=0.078$ ). When age was analyzed by groups, most patients were between 41 and 60 years of age ( $n=72,57.6 \%)$, followed by those who were older than 60 years $(23.2 \%)$ and those younger than 40 years (19.2\%).

Of the totality of cases, $18.4 \%(n=23)$ received continuous care at the emergency department and $81.6 \%(n=102)$ were admitted to the reconverted area for COVID-19.

\section{Comorbidities}

Twenty-seven patients (21.6\%) had type 2 diabetes mellitus, with a mean evolution time of 10.93 years (range, 1 to 40 ), with this time being longer for the female gender (13.4 versus 8.2 years, $\mathrm{p}=0.151,95 \% \mathrm{Cl},-2.0$ to 12.4$)$. The drug that was mainly used for metabolic control was metformin $(77.8 \%, n=21)$, followed by different types of insulin $(11.1 \%, n=3)$; two cases resorted to naturist treatment $(7.4 \%, n=2)$. Twenty-three patients (18.4\%) had hypertension, with age being significantly more advanced in these cases (60 versus 49 years, $p$ $=0.000$ ); mean number of years with hypertension was 12.43 (range, 5 to 40 ). Angiotensin receptor antagonists 

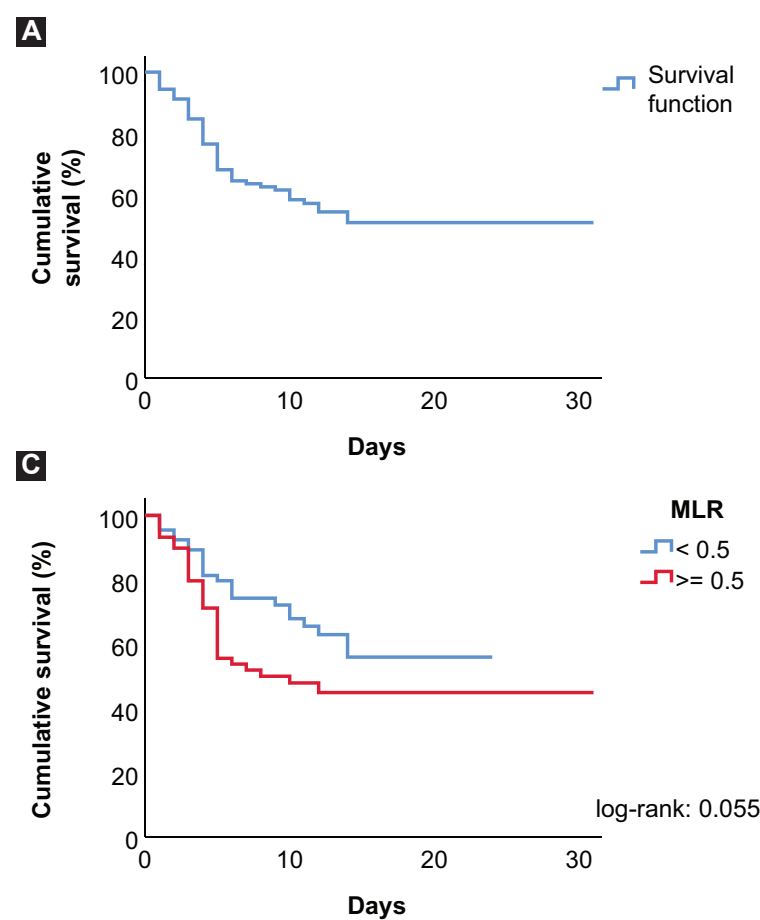
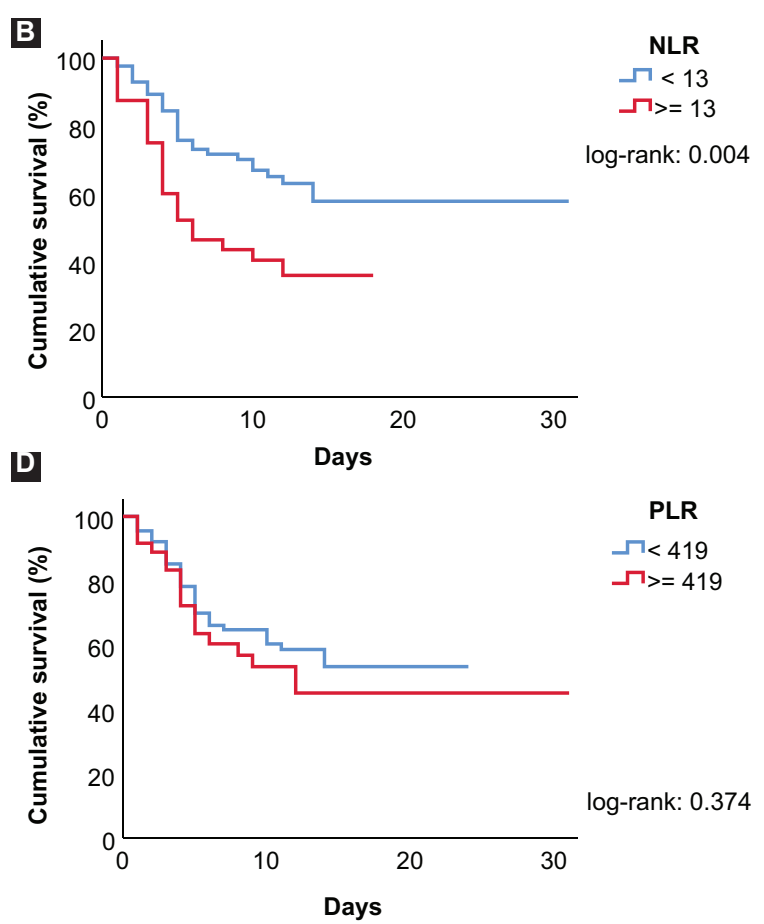

Figure 1. Survival of patients hospitalized for COVID-19. A) Survival curve; B) COVID-19 survival curve stratified by NLR; C) COVID-19 survival curve stratified by MLR; D) COVID-19 survival curve stratified by PLR. NLR = neutrophil-to-lymphocyte ratio, MLR = monocyte-to-lymphocyte ratio, PLR = platelet-to-lymphocyte ratio.

were the main treatment: losartan, irbersartan and telmisartan $(52.2 \%, n=12)$, followed by angiotensin converting enzyme inhibitors (21.7 \%, $n=5)$ : enalapril, and captopril. Thirty-three patients $(26.4 \%)$ had both comorbidities (diabetes and hypertension), and $5.6 \%(n=7)$, only one.

Other comorbidities were recorded: hypothyroidism $(n=2,16 \%)$, chronic pulmonary disease $(4 \%, n=5)$, epilepsy, rheumatoid arthritis and human immunodeficiency virus infection (one case each, $0.8 \%$ ).

\section{Blood count}

Blood count means, ranges and differences among surviving and deceased patients are summarized in table 1 . Twenty seven cases (21.6\%) showed absolute eosinopenia at diagnosis; thrombocytopenia was identified in three cases $\left(<100 \times 10^{3} / \mu \mathrm{L}\right)$, and platelet count was higher than $450 \times 10^{3} / \mu \mathrm{L}$ in six.

\section{Events}

Fifty-four deaths (43.2 \%) occurred in the 30 -day follow-up, with mean survival being $18.5 \pm 1.2$ days (Fig. 1). Twenty patients (16\%) underwent ventilatory support.

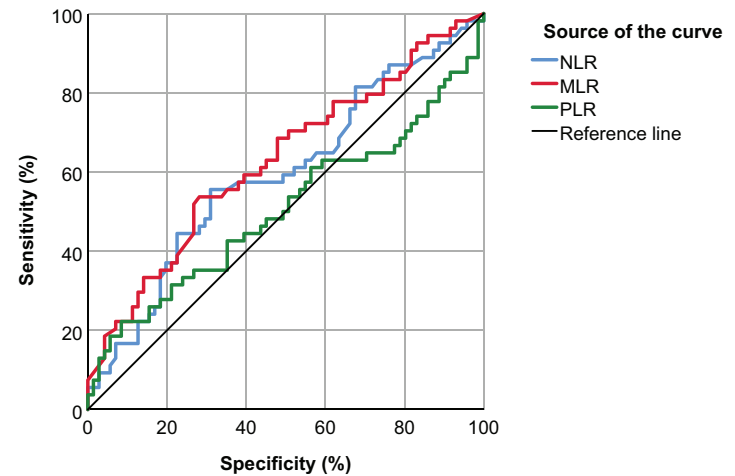

Figure 2. ROC curves for the three ratios with regard to mortality prognosis in patients hospitalized for COVID-19.

\section{Blood ratios}

Mean NLR, PLR and MLR were 12.01 (range, 1.9 to 56), 373.07 (range, 0 to 2136), and 0.442 (range, 0 to 2.0 ), respectively. No differences in mean ratios were identified when they were stratified by the presence of comorbidities (NLR: $p=0.780,95 \% \mathrm{Cl}$ : -3.109 4.1353; PLR: $p=0.415,95 \%$ Cl: $-76.015-182.88$, MLR: $p=0.102,95 \%$ Cl: $-0.203-0.221)$. 
Table 2. Association of different variables with the prognosis of patients hospitalized for COVID-19

\begin{tabular}{|c|c|c|c|c|c|c|}
\hline \multirow[t]{2}{*}{ Condition } & \multicolumn{3}{|c|}{ Death } & \multicolumn{3}{|c|}{ Ventilatory support } \\
\hline & OR & $95 \% \mathrm{Cl}$ & p & OR & $95 \% \mathrm{Cl}$ & $p$ \\
\hline Diabetes & 0.379 & $0.1472-0.9797$ & 0.045 & 0.891 & $0.2714-2.9277$ & 0.849 \\
\hline Comorbidities & 0.486 & $0.2222-1.0672$ & 0.072 & 1.124 & $0.4113-3.0740$ & 0.819 \\
\hline Male gender & 0.697 & $0.3339-1.4550$ & 0.336 & 1.053 & $0.3870-2.8671$ & 0.919 \\
\hline Age $>50$ years & 1.790 & 0.8657 to 3.7049 & 0.116 & 3.636 & $1.1392-11.6077$ & 0.029 \\
\hline Lymphocytes $<0.5$ & 0.638 & $0.2772-1.4711$ & 0.292 & 3.477 & $1.2707-9.5153$ & 0.015 \\
\hline Leukocytes > 10 & 1.565 & $0.6798-3.6074$ & 0.292 & 1.528 & $0.5281-4.4205$ & 0.434 \\
\hline$N L R>13$ & 2.750 & $1.2690-5.9593$ & 0.001 & 1.953 & $0.7362-5.1814$ & 0.178 \\
\hline MLR > 0.5 & 2.069 & $1.0082-4.2497$ & 0.047 & 1.851 & $0.6990-4.9016$ & 0.215 \\
\hline PLR $>419$ & 1.472 & $0.676-3.207$ & 0.330 & 1.411 & $0.512-3.888$ & 0.505 \\
\hline
\end{tabular}

$\mathrm{OR}=$ odds ratio, $\mathrm{Cl}=$ confidence interval, $\mathrm{NLR}=$ neutrophil-to-lymphocyte ratio, $\mathrm{MLT}=$ monocyte-to-lymphocyte ratio, $\mathrm{PLR}=$ platelet-to-lymphocyte ratio.

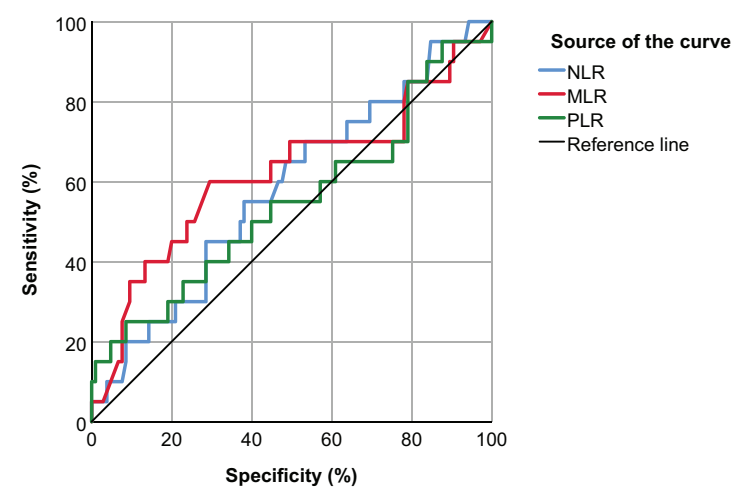

Figure 3. ROC curves for the three ratios with regard to ventilatory support prognosis in patients hospitalized for COVID-19.

\section{Prognostic factors}

In those patients who died, mean MLR, PLR and NLR were 0.537, 419 and 13.9, respectively, with these values being used as cutoff points to establish the risk for mechanical ventilation, death and other clinical variables (Table 2). The ROC curves for the ratios with regard to mortality and mechanical ventilation use are shown in figures 2 and 3 . The presence of a NLR $>13(p=0.001)$ and MLR $>0.5(p=0.047)$ were related to a higher risk of death; PLR did not show a relationship with mortality $(p=0.432)$ or mechanical ventilation $(p=0.160)$. None of the analyzed factors increased the risk for ventilatory support.

The differentiated analysis of the survival curves indicates that a NLR > 13 (log-rank: 0.004) and a MLR > 0.5 (log-rank: 0.055 ) were significantly associated with lower survival, and that LPR did not significantly impact survival (log-rank: 0.374), as observed in figure 1 ( $B, C$ and $D$, respectively).

\section{Discussion}

Despite the measures implemented by the health system, a large part of hospital centers only have basic routine laboratory tests for the care of patients with SARS-CoV-2 infection. Among these tests, blood counts have been highly useful for identifying those patients with potential risk of complications. The main purpose of this study was to assess the usefulness of three easy-to-obtain, low-cost blood ratios in the prediction of complications associated with SARS-CoV-2 infection. Both NLR and MLR were useful to identify patients at higher risk of death, unlike LPR, which had a lower area under the curve and was not useful for predicting those cases that required ventilatory support. The presence of severe lymphopenia was directly associated with ventilatory support.

These data are consistent with those reported by Zhang et al., who referred that lymphopenia was a constant finding among 663 patients with COVID-19, especially in critically ill patients $(87.2 \%)$ who required ventilatory support. ${ }^{17}$ In turn, Wang et al. assessed the impact of different clinical and laboratory variables on prognosis. In their series, leukocyte counts were slightly higher in those patients who ultimately died (4.4 vs. $6.7 \times 10^{3} / \mu \mathrm{L}, p=0.004$ ), as well as neutrophil counts ( 2.8 vs. $\left.5.4 \times 10^{3} / \mu \mathrm{L}, p=0.001\right)$; in the univariate model, both age and gender were independent risk factors. ${ }^{18}$ In our results, both age and the male gender behaved as risk factors for mortality.

Regarding the ratios, NLR was one of the main ones for predicting complications associated with COVID-19. This ratio reflects individual inflammatory state and is highly useful in bacterial pneumonias, with its value being consistent with scores such as those of CURB65.19 In bacterial pneumonia, NLR 
ranges from 8 to 13, unlike tuberculosis infection, where its value is lower than $7.20-22$ In SARS-CoV-2 infection, this ratio is among the proposed severity biomarkers together with C-reactive protein, serum amyloid peptide, interleukin-6, lactate dehydrogenase, D-dimer, troponin, and some renal biomarkers. ${ }^{23}$ Liu et al. identified that NLR was independently associated with mortality: cases with a value between 4.85 and 88.09 were significantly associated with respiratory complications, with an OR of 16.04 $(p=0.0001) .{ }^{24}$ Recently, in Louisiana (USA), Tatum et al. recorded that this ratio (with a cutoff value of 4.94) was associated with the risk of ventilatory support use and hospital mortality. ${ }^{25}$

Finally, regarding MLR and PLR, their usefulness in patients with COVID-19 has not been established. In our study, the ratio that showed the highest usefulness was MLR, mainly due to the role of monocytes on the initial state of inflammation associated with COVID-19. Lu et al. described the evolutionary behavior of blood count in COVID-19, where monocyte, eosinophil and lymphocyte counts showed a recovery after day 15 of disease onset. ${ }^{26}$ These data support the role of monitoring these ratios not only at diagnosis but during disease follow-up.

Currently, SARS-CoV-2 infection is at its highest peak in Latin America, despite the strategies implemented by the different ministries of health; there are still hospitals that only have routine tests to monitor the disease. Ratios based on blood counts are easily accessible; NLR and MLR and can predict SARSCoV-2 infection-associated mortality.

\section{Acknowledgements}

Our affectionate and respectful gratitude to all the personnel of the medical units (nurses, doctors, infection control staff, laboratory technicians, receptionists and other collaborators), who continue to offer the best possible care, even doing the impossible with the scarce resources they sometimes have available. A deserved posthumous recognition to the members of the Cuautitlán Hospital nursing staff who unfortunately have lost their lives in this pandemic.

\section{Conflict of interests}

The authors declare that they have no conflicts of interest.

\section{Funding}

The authors received no sponsoring to carry out this article.

\section{Ethical disclosures}

Protection of human and animal subjects. The authors declare that the procedures followed adhered to the ethical standards of the responsible human experimentation committee and were in agreement with the World Medical Association and the Declaration of Helsinki.

Confidentiality of data. The authors declare that they have followed the protocols of their work center on the publication of patient data.

Right to privacy and informed consent. The authors declare that no patient data appear in this article.

\section{References}

1. Johns Hopkins University School of Medicine [Internet]. USA: COVID-19 map; 2020.

2. Secretaria de Salud [Internet]. Mexico: Coronavirus (COVID-19)-Comunicado técnico diario; 2020.

3. Zhou F, Yu T, Du R, Fan G, Liu Y, Liu Z, et al. Clinical course and risk factors for mortality of adult inpatients with COVID-19 in Wuhan, China: a retrospective cohort study. Lancet. 2020;395:1054-1062.

4. Gebhard C, Regitz-Zagrosek V, Neuhauser HK, Morgan R, Klein SL Impact of sex and gender on COVID-19 outcomes in Europe. Biol Sex Differ. 2020;11:9.

5. Guan WJ, Liang WH, Zhao Y, Liang HR, Chen ZS, Li YM, et al. Comorbidity and its impact on 1,590 patients with Covid-19 in China: a nationwide analysis. Eur Respir J. 2020;55:2000547.

6. Li X, Xu S, Yu M, Wang K, Tao Y, Zhou Y, et al. Risk factors for severity and mortality in adult COVID-19 inpatients in Wuhan. J Allergy Clin Immunol. 2020;146:110-118.

7. Zhao Q, Meng M, Kumar R, Wu Y, Huang J, Deng Y, et al. Lymphopenia is associated with severe coronavirus disease 2019 (COVID-19) infections: a systemic review and meta-analysis. Int $\mathrm{J}$ Infect Dis. 2020;96:131-135.

8. Gürağaç $A$, Demirer Z The neutrophil-to-lymphocyte ratio in clinical practice. Can Urol Assoc J. 2016;10:141.

9. Che-Morales J, Cortés-Télles A. Neutrophil-to-lymphocyte ratio as a serum biomarker associated with community acquired pneumonia. Rev Med Inst Mex Seguro Soc. 2018;56:537-543.

10. Ciccullo A, Borghetti A, Dal Verme LZ, Tosoni A, Lombardi F, Garcovich $\mathrm{M}$, et al. Neutrophil-to-lymphocyte ratio and clinical outcome in COVID-19: a report from the Italian front line. Int J Antimicrob Agents. 2020;56:106017.

11. Kurtipek E, Tahir-Bekci T, Kesli R, Sami-Sami S, Terzi Y. The role of neutrophil-lymphocyte ratio and platelet-lymphocyte ratio in exacerbation of chronic obstructive pulmonary disease. J Park Med Assoc. 2015;65:1283-1287.

12. Kadiyoran C, Zengin O, Cizmecioglu HA, Tufan A, Kucuksahin O, Cure $\mathrm{MC}$, et al. Monocyte to lymphocyte ratio, neutrophil to lymphocyte ratio, and red cell distribution width are the associates with gouty arthritis. Acta Medica (Hradec Kralove). 2019;62:99-104.

13. Gao K, Zhu W, Liu W, Ma D, Li H, Yu W, et al. Diagnostic value of the blood monocyte-lymphocyte ratio in knee osteoarthritis. J Int Med Res. 2019;47:4413-4421.

14. Coperchini F, Chiovato L, Croce L, Magri F, Rotondi M. The cytokine storm in COVID-19: an overview of the involvement of the chemokine/chemokine-receptor system. Cytokine Growth Factor Rev. 2020; 53:25-32.

15. Colling ME, Kanthi Y. COVID-19-associated coagulopathy: an exploration of mechanisms. Vasc Med. 2020.

16. MDCalc [Online]. USA: MDCalc; 2020. 
17. Zhang J, Wang X, Jia X, Li J, Hu K, Chen G, et al. Risk factors for disease severity, unimprovement, and mortality in COVID-19 patients in Wuhan, China. Clin Microbiol Infect. 2020;26(6):767-772

18. Wang D, Yin Y, Hu C, Liu X, Zhang X, Zhou S, et al. Clinical course and outcome of 107 patients infected with the novel coronavirus, SARS CoV-2, discharged from two hospitals in Wuhan, China. Crit Care. 2020;24:188.

19. de Jager CPC, Wever PC, Gemen EFA, Kusters R, van Gageldonk-Lafeber $\mathrm{AB}$, van der Poll $\mathrm{T}$, et al. The neutrophil-lymphocyte count ratio in patients with community-acquired pneumonia. PLoS One. 2012; $7: e 46561$.

20. Curbelo J, Rajas O, Arnalich B, Galván-Román JM, Luquero-Bueno S Ortega-Gómez $M$, et al. Neutrophil count percentage and neutrophil-lymphocyte ratio as prognostic markers in patients hospitalized for community-acquired pneumonia. Arch Bronconeumol. 2019; 55:472-477.
21. Yoon NB, Son C, Um SJ. Role of the neutrophil-lymphocyte count ratio in the differential diagnosis between pulmonary tuberculosis and bacterial community-acquired pneumonia. Ann Lab Med. 2013;33:105-110.

22. Cataudella E, Giraffa CM, Di Marca S, Pulvirenti A, Alaimo S, Pisano M, et al. Neutrophil-to-lymphocyte ratio: an emerging marker predicting prognosis in elderly adults with community-acquired pneumonia. J Am Geriatr Soc. 2017;65:1796-1801.

23. Kermali M, Khalsa RK, Pillai K, Ismail Z, Harky A. The role of biomarkers in diagnosis of COVID-19 - A systematic review. Life Sci. 2020:254:117788.

24. Liu Y, Du X, Chen J, Jin Y, Peng L, Wang HHX, et al. Neutrophil-to-lymphocyte ratio as an independent risk factor for mortality in hospitalized patients with COVID-19. J Infect. 2020;81:e6-e12.

25. Tatum D, Taghavi S, Houghton A, Stover J, Toraih E, Duchesne J. Neutrophil-to-lymphocyte ratio and outcomes in Louisiana Covid-19 patients. Shock. 2020.

26. Lu G, Wang J. Dynamic changes in routine blood parameters of a severe COVID-19 case. Clin Chim Acta. 2020;508:98-102. 